\title{
A SIMPLE METHOD FOR DETERMINING THE SYSTOLIC BLOOD PRESSURE OF THE UNANESTHETIZED RAT ${ }^{1}$
}

\author{
By J. R. WILlIAMS, JR., T. R. HARRISON, AND A. GROLLMAN \\ (From the Department of Medicine, Vanderbilt University School of Medicine, Nashville, and \\ the Department of Pharmacology, Johns Hopkins Medical School, Baltimore)
}

(Received for publication January 30, 1939)

Despite the importance of the determination of blood pressure in the experimental laboratory animals, most of the methods in common use are unsatisfactory. Many of the procedures are applicable only to the anesthetized animal and hence give results which deviate from those observed in the normal animal. Various indirect methods which do not demand the sacrifice of the animal have been described but these usually involve the use of complicated and costly apparatus and are often fraught with grave errors. The difficulty of determining the blood pressure in the rat has excluded the use of this species in many studies for which it offers ideal advantages over the larger mammals. As part of our studies on experimental hypertension we have devised a simple, cheaply constructed apparatus by the use of which it is possible to determine easily and rapidly the systolic blood pressure of the unanesthetized rat. Determinations on as many as one hundred animals may be made in a single day without diffculty.

\section{APPARATUS ${ }^{2}$}

The apparatus consists of a warming box, a suitable holder for the rat, a compression cuff, and a plethysmograph. The rat holder is made of a piece of thin-walled brass tubing $(A)$ (see Figure 1), 6 centimeters in diameter and 10 centimeters long. One end of this is open and the other closed except for a round hole $(B) 2$ centimeters in diameter, through which to bring the rat's tail. This brass cylinder fits into a copper sleeve $(C)$ of similar length, one end of which is closed with copper screening. If serial

1 This work was aided by grants from the Josiah Macy, Jr., Foundation and from Mr. Joe Werthan.

2 We are indebted to Mr. M. Herblin, Director of the Apparatus Shop, Vanderbilt Medical School, for technical assistance in the designing and construction of this apparatus. pressures are to be taken on the same rat the outer jacket is wound with a heating coil $(D)$ and connected to a rheostat $(E)$. We have used the unit from a flat-iron. A thermometer $(F)$ is placed near the closed end of the outer tube, which is covered with gauze bandage to permit even distribution of heat.

The blood pressure cuff $(G)$ is a modification of that used by Diaz and Levy (1). It is a brass tube 4 centimeters in diameter and 4 centimeters long. A 1.8 centimeter hole $(H)$ is made in the proximal end and a 1.5 centimeter hole $(I)$ in the distal end. A flange $(J)$ is built around these to facilitate the placing of the rubber tubing as shown in the insert in Figure 1. Thin-walled soft rubber tubing $(K)$ one centimeter in diameter, such as that used for surgical drainage, is then threaded through the holes and carefully fitted over the flanges so as to produce a smooth round aperture. The tubing is held in place by tightly fitting metal inserts ( $L$ and $M$ ), as shown in Figure 1. A side connection leads through a T-tube to a mercury manometer $(N)$ and a sphygmomanometer bulb and release valve $(O)$.

The plethysmograph $(P)$ is made of 2-centimeter brass tubing 13 centimeters long, the ends being constructed the same as the distal end of the pressure cuff. The same kind of rubber tubing used in the pressure cuff is used in the plethysmograph. In putting this in place one must be careful it is not stretched, for 5 centimeters of water pressure must hold it against the tail. The two cuffs are then fastened together, as shown in Figure 1. A side connection leads through a short piece of pressure tubing to a three-way tap $(Q)$, which is connected to a 20 cubic centimeter syringe $(R)$ and a water manometer $(S)$ made of $1 / 8$ th inch glass tubing. The rubber connection should be as short as possible. The manometer, syringe, and plethysmograph are then filled with water. 


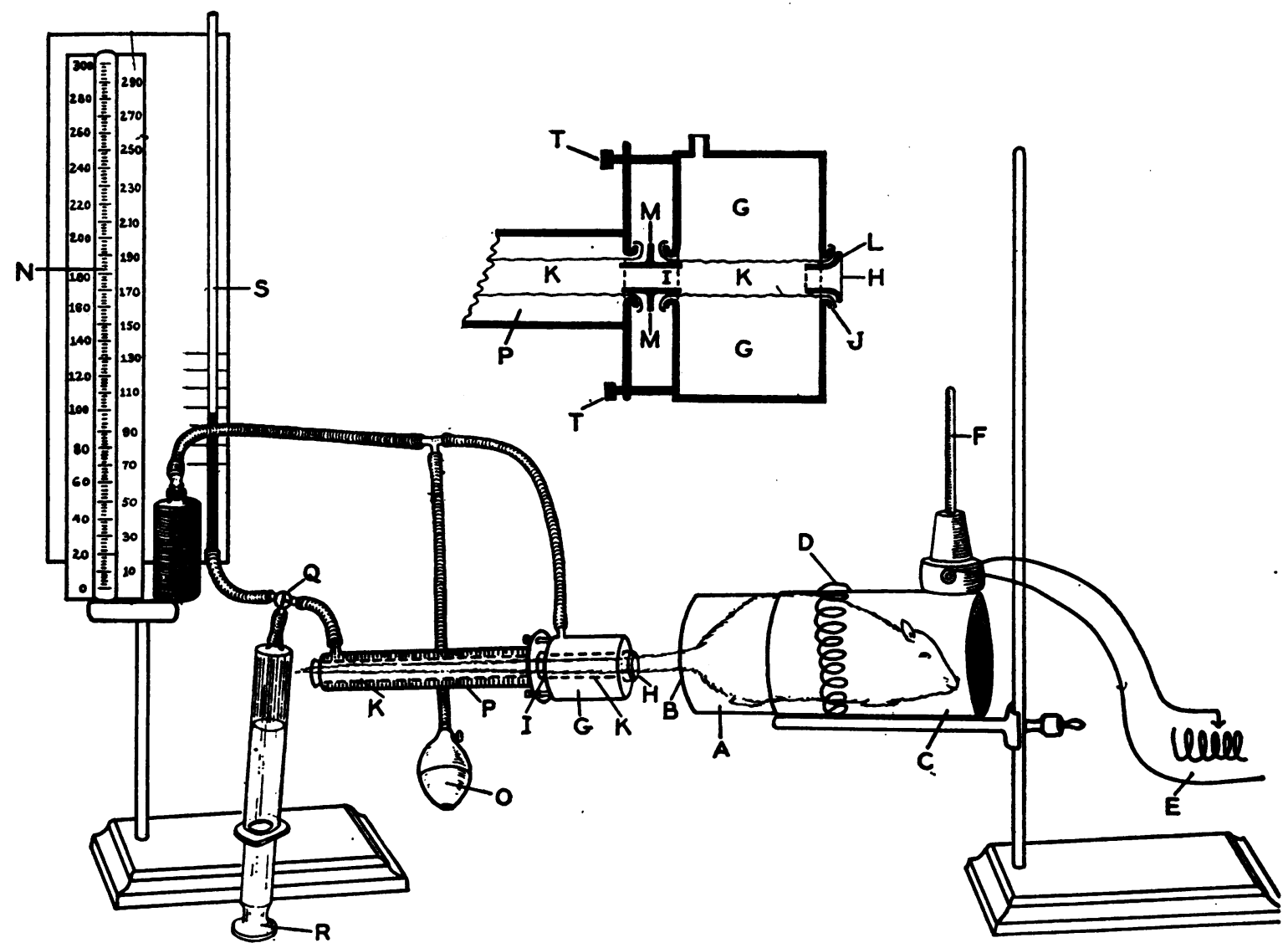

Fig. 1. Blood Pressure Apparatus and Rat Holder

$A$. Brass can for holding rat; $B$. Hole for rat's tail; $C$. Copper sleeve into which $A$ slides; $D$. Heating unit from flat iron; $E$. Variable resistance; $F$. Thermometer; $G$. Pressure cuff; $H$. and $I$. Holes through which tail is drawn; $J$. Flange to hold rubber tubing; $K$. Thin-walled rubber tubing; $L$. and $M$. Metal insert to hold tubing between pressure and plethysmograph chambers; $N$. Mercury manometer; $O$. Inflation bulb and air release valve; $P$. Plethysmograph chamber; $Q$. Three-way tap; $R$. 20 cc. syringe; $S$. Water manometer; $T$. Screws for holding together the plethysmograph and pressure chambers.

The insert shows details of construction of blood pressure cuff and plethysmograph. For further details and operation, see text.

\section{METHOD}

Grant (2) has shown that small arteries are constantly changing in caliber, and that heating the animal will release this intermittent vasoconstriction. It is not possible to secure blood pressure readings with our apparatus without heating the rat. Byrom and Wilson (3), using a much more sensitive plethysmograph, obtained satisfactory readings but were forced to use anesthesia. By adopting the criteria described below, it is easy to secure accurate blood pressure readings in a trained, unanesthetized but warmed rat.

The rat is placed in the warming box, which is kept at a temperature between 40 and $42^{\circ} \mathrm{C}$., for 5 to 10 minutes. We use a cylindrical cardboard box with a tight fitting cover 20 centimeters in diameter and 30 centimeters deep. An ordinary light bulb connected to a rheostat is placed in the bottom of the box. About midway in the box is placed a wire screen which when covered with cardboard furnishes a platform for the rats. Any similar box with lights will do. It is not necessary to measure the body temperature as the character of the reading will determine whether sufficient vasodilatation has been induced. (If a single pressure is to be taken 
one need not heat the rat holder. If repeated pressures are desired, however, one can maintain the necessary vasodilatation by keeping the holder at approximately $37^{\circ} \mathrm{C}$.) On removal from the warming box the rat is placed in the holder and the tail is inserted through the hole into the cuff and the plethysmograph. Gentle pressure is then applied through the syringe. The pressure cuff is inflated above the systolic level, the syringe is released, and the three-way tap turned to connect the water manometer and the plethysmograph. Five to 15 centimeters of water pressure are sufficient to compress the recording cuff snugly around the tail. Air is now slowly released until the water level begins to rise. Under proper conditions this point represents systolic blood pressure. If the rat is properly heated neither restlessness nor sweating will occur, and when the reading is taken there will be a sharp increase in the rate of rise in the water manometer before the mercury manometer has been lowered 10 millimeters below the systolic level. The water level should rise at least a centimeter during this period and should continue rising as the cuff is deflated, until the pressure is almost off, when a drop occurs. Successive readings should yield pressures in the same range. A steady rise or fall in successive readings indicates the rat is not properly heated. If one raises the rectal temperature to $40^{\circ} \mathrm{C}$., accurate readings will usually be obtained. If the above criteria are used it is not necessary to measure the temperature.

One of the more frequent causes of error in the method is overheating of the animals, which causes restlessness and false high blood pressure readings. If the rats are heated to the point of collapse, false low blood pressure readings are obtained. On the other hand, false low readings result from insufficient heating. However, this can be avoided by making sure the rises of the water manometer fulfill the aforementioned criteria and having successive pressures fall within the same range. Air pockets in the plethysmograph make readings difficult. Poorly trained rats will not give consistent pressures. The blood pressure cuff should have at least 3 centimeters of rubber in contact with the tail. Less than this may result in false pressure readings. Another common source of error is having the rubber tub- ing placed improperly in the plethysmograph. It should be smooth and even and under no tension. If all these criteria are properly fulfilled, accurate blood pressures on rats are readily obtained.

\section{RESULTS}

The systolic blood pressures of a group of young adult rats as determined daily for six days (after a period of preliminary training to habituate the animals to the apparatus) are reproduced in Table I. The values obtained illustrate

TABLE I

The blood pressure of the normal rat as determined on five successive days

\begin{tabular}{c|c|c|c|c|c}
\hline \hline $\begin{array}{c}\text { Rat } \\
\text { number }\end{array}$ & \multicolumn{5}{|c}{ Blood pressure on 5 successive days (mm. $\left.H_{0}\right)$} \\
\hline 1 & 120 & 115 & 120 & 110 & 120 \\
2 & 100 & 110 & 110 & 105 & 110 \\
3 & 115 & 125 & 110 & 115 & 120 \\
4 & 100 & 110 & 110 & 100 & 105 \\
5 & 110 & 115 & 120 & 120 & 115 \\
\hline
\end{tabular}

the excellent day-to-day reproducibility of the values when precautions are taken to avoid excitement, overheating, etc., and when the animals have become accustomed to the procedure. The values of Table I are of the same order of magnitude as those observed by us on numerous animals by direct manometric measurement with a cannula inserted into the aorta in rats anesthetized with nembutal. The values are also in good agreement with those reported by Durant (4) and Leiter (5), using direct manometric measurement. They are also in fair agreement but show much less variation than those reported by Griffith et al. (6) and Bonsmann (7) using indirect procedures. Woodbury and Hamilton (8), on the other hand, report values of 145 and 187, respectively, on two rats as measured by the optical manometer.

We have also applied the apparatus for prolonged studies of the blood pressure on rats in which hypertension has been induced. Typical results showing the high degree of reproducibility of the results obtained on such animals are given in Table II. The determinations were always made at the same hour of the day and the animals maintained on a constant diet.

The values reported by Silfverskiöld (9) for 
TABLE II

The blood pressure of hypertensive rats as determined on five successive days

\begin{tabular}{c|c|c|c|c|c}
\hline \hline $\begin{array}{c}\text { Rat } \\
\text { number }\end{array}$ & \multicolumn{5}{|c}{ Blood precesure on 5 succeseive days $\left(\boldsymbol{m m} . \boldsymbol{H}_{\mathrm{g}}\right)$} \\
\hline & 165 & 170 & 165 & 170 & 170 \\
1 & 160 & 190 & 170 & 170 & 170 \\
2 & 160 & 160 & 150 & 160 & 150 \\
3 & 150 & 140 & 140 & 140 & 150 \\
4 & 150 & 160 & 155 & 160 & 150 \\
5 & 150 & & & &
\end{tabular}

the mouse range from 12 to $16 \mathrm{~mm}$. $\mathrm{Hg}$. Such values are obviously low and incompatible with our generally accepted notions concerning the hemodynamics of the circulation. Determinations with a small-scale glass model of the apparatus pictured in Figure 1 on adult mice gave values only slightly lower than those observed on rats. Silfverskiöld adopted the method of Roy and Brown (10) in which one observes the cessation of the blood flow in a transilluminated limb enclosed in a compression chamber. His results illustrate the errors possible despite the apparent simplicity of the procedure. Our own results for the mouse are in agreement with those reported by Bonsmann.

The apparatus and general method described in the present paper, as applied to the rat, are possibly generally applicable to other species such as the mouse, cat or dog, when the size of the apparatus is modified to conform to the size of the tail in these animals. The apparatus can serve as a simple means in any experiment where measurements are desired on the unanesthetized animal.

\section{SUMMARY}

A method is described for measuring the systolic blood pressure in the tail of the intact unanesthetized rat, which when modified as to size, is suitable for use on other animals.

\section{BIBLIOGRAPHY}

1. Diaz, J. T., and Levy, S. E., An indirect method for repeated determinations of blood pressure of rats. Proc. Soc. Exper. Biol. and Med., 1939, 40, 402.

2. Grant, R. T., Further observations on the vessels and nerves of the rabbit's ear, with special reference to the effect of denervation. Clin. Sc., 1935, 3, 1.

3. Byrom, F. B., and Wilson, C., A plethysmographic method for measuring blood pressure in the rat. J. Physiol., 1938, 93, 301.

4. Durant, R. R., Blood pressure in the rat. Am. J. Physiol., 1927, 81, 679.

5. Leiter, L., Nonspecific role of pressor substances in plasma of hypertensive patients. Arch. Int. Med., 1936, 57, 729.

6. Griffith, J. Q., Jeffers, W. A., and Lindauer, M. A., Study of mechanism of hypertension following intracisternal kaolin injection of rats; leucocytic reaction and effect on lymphatic absorption. Am. J. Physiol., 1935, 113, 285.

7. Bonsmann, M. R., Blutdruckversuche an der Maus und Ratte mittels Photozelle. Arch. f. exper. Path. u. Pharmakol., 1934, 176, 460.

8. Woodbury, R. A., and Hamilton, W. F., Blood pressure studies in small animals. Am. J. Physiol., 1937, 119, 663.

9. Silfverskiöld, B. P., Uber den arteriellen Blutdruck bei der weissen Maus. Skandinav. Arch. f. Physiol., 1937, 77, 139.

10. Roy, C. S., and Brown, J. G., The blood pressure and its variations in the arterioles, capillaries and smaller veins. J. Physiol., 1879, 2, 323. 